OPEN ACCESS

Edited by:

Isabelle Caroline Le Poole,

Northwestern University,

United States

Reviewed by:

Jillian M. Richmond,

University of Massachusetts Medical

School, United States

Mauro Picardo,

San Gallicano Hospital, Italy

${ }^{*}$ Correspondence:

Rasheedunnisa Begum

rasheedunnisab@yahoo.co.in

Specialty section:

This article was submitted to

Autoimmune and

Autoinflammatory Disorders,

a section of the journal

Frontiers in Immunology

Received: 31 October 2020 Accepted: 22 December 2020 Published: 04 February 2021

Citation:

Jadeja SD, Mayatra JM, Vaishnav J, Shukla N and Begum R (2021) A

Concise Review on the Role of

Endoplasmic Reticulum Stress in the

Development of Autoimmunity in

Vitiligo Pathogenesis.

Front. Immunol. 11:624566.

doi: 10.3389/fimmu.2020.624566

\section{A Concise Review on the Role of Endoplasmic Reticulum Stress in the Development of Autoimmunity in Vitiligo Pathogenesis}

\author{
Shahnawaz D. Jadeja, Jay M. Mayatra, Jayvadan Vaishnav, Nirali Shukla \\ and Rasheedunnisa Begum* \\ Department of Biochemistry, Faculty of Science, The Maharaja Sayajirao University of Baroda, Vadodara, India
}

Vitiligo is characterized by circumscribed depigmented macules in the skin resulting due to the autoimmune destruction of melanocytes from the epidermis. Both humoral as well as cell-mediated autoimmune responses are involved in melanocyte destruction. Several studies including ours have established that oxidative stress is involved in vitiligo onset, while autoimmunity contributes to the disease progression. However, the underlying mechanism involved in programing the onset and progression of the disease remains a conundrum. Based on several direct and indirect evidences, we suggested that endoplasmic reticulum (ER) stress might act as a connecting link between oxidative stress and autoimmunity in vitiligo pathogenesis. Oxidative stress disrupts cellular redox potential that extends to the ER causing the accumulation of misfolded proteins, which activates the unfolded protein response (UPR). The primary aim of UPR is to resolve the stress and restore cellular homeostasis for cell survival. Growing evidences suggest a vital role of UPR in immune regulation. Moreover, defective UPR has been implicated in the development of autoimmunity in several autoimmune disorders. ER stress-activated UPR plays an essential role in the regulation and maintenance of innate as well as adaptive immunity, and a defective UPR may result in systemic/tissue level/organ-specific autoimmunity. This review emphasizes on understanding the role of ER stress-induced UPR in the development of systemic and tissue level autoimmunity in vitiligo pathogenesis and its therapeutics.

Keywords: endoplasmic reticulum, unfolded protein response, vitiligo, melanocytes, autoimmunity

\section{INTRODUCTION}

Extensive research over the years established that a complex interaction between genetic, environmental, biochemical, and immunological factors collectively generate a microenvironment favoring melanocyte loss in vitiligo (1-3). The complex genetics of vitiligo involves multiple susceptibility loci, incomplete penetrance, and genetic heterogeneity with gene-gene and geneenvironment interactions and altered miRNA expression (Table S1) (4-6). Accumulation of oxidative stress due to defective recycling of tetrahydrobiopterin, mitochondrial impairment 
(Table S2), and compromised antioxidant system are reported in vitiligo patients (7-11). This accumulated oxidative stress might result in DNA damage, lipid and protein peroxidation, neoantigen formation, and may affect normal melanogenesis in melanocytes (12). Moreover, both humoral and cellular autoimmunity, altered $\mathrm{CD} 4^{+} / \mathrm{CD}^{+} \mathrm{T}$ cell ratio, decreased regulatory $\mathrm{T}$ cells (Tregs) function, presence of autoreactive anti-melanocyte $\mathrm{CD}^{+} \mathrm{T}$ cells in both blood and skin, as well as imbalance of pro- and anti-inflammatory cytokine levels are reported to be involved in vitiligo pathogenesis (2, 13-20). Our extensive population based studies indicated impeded redox and immune homeostasis in the skin and blood of vitiligo patients from Gujarat population (2, 14, 17, 21-41). Hence, based on our observations, we proposed that oxidative stress triggers vitiligo onset, while autoimmunity contributes to the disease progression (2). Despite extensive research, the exact mechanism which connects the triggering factors with the disease progression is still obscure. Investigating the connecting link between the factors involved in onset and progression of vitiligo may enhance our understanding of its pathomechanisms and thereby open new avenues for development of novel therapeutic strategies.

It has been reported that melanocytes from vitiligo patients had dilated endoplasmic reticulum (ER) as compared to healthy melanocytes (42). The accumulation of misfolded proteins in the ER lumen and its dilation are the characteristics of ER stress. Excessive load of protein folding in ER may also generate oxidative stress (43). Several studies suggested the generation of ROS during normal protein folding process in ER and oxidation of ER proteins under oxidative stress led to the accumulation of misfolded proteins $(44,45)$. Interestingly, vitiligo patients are reported to have significantly elevated homocysteine levels which may induce oxidative stress, ER stress, and expression of pro-inflammatory cytokines (28, 46, 47). Unfolded protein response (UPR) upon ER stress is also known to regulate the innate immune response in different ways (48). Based on several direct and indirect evidences, earlier we speculated that ER stress could be a major link between oxidative stress and autoimmunity, which might play a key role in the onset and exacerbation of vitiligo (49). In this review, we will emphasize on the potential role of ER stress in the development of autoimmune/inflammatory responses in vitiligo.

\section{UNDERSTANDING ER STRESS-INDUCED UPR}

The ER is an active intracellular organelle with different functions like protein folding and maturation within the eukaryotic cell, essential for cellular homeostasis, proteostasis, cellular development, and stress responsiveness (50). Aberrations in protein folding may result in an imbalance leading to the accumulation of misfolded proteins in the ER, which is known as ER stress. To combat ER stress, the cell activates UPR which may alleviate ER stress through global translation attenuation, induction of chaperones, degradation of misfolded proteins by ER-associated degradation (ERAD), and apoptosis (51). The accumulation of misfolded proteins increases the production of BiP/GRP78 (78-kDa glucose-regulated protein) (52). GRP78 forms dynamic stability between the nascent polypeptides (unfolded proteins) and intra-luminal domains of the three ER stress sensors viz. inositol-requiring enzyme $1 \alpha$ (IRE1 $\alpha$ ), PKR like endoplasmic reticulum kinase (PERK), and activating transcription factor 6 (ATF6) (53-56). In non-stress conditions, all three sensors are primarily bound with GRP78, which helps to maintain its inactive state. The fate of the stressed cell towards survival or death depends upon the interplay among these three major arms of the UPR signaling pathways $(57,58)$ (Figure 1).

\section{ROLE OF UPR IN INFLAMMATION AND IMMUNE REGULATION}

The UPR has emerged as a hallmark of several diseases including inflammatory bowel disease, arthritis, neurodegenerative diseases, diabetes mellitus, stroke, and cancer (58-60). UPR plays a vital role in inflammation, mainly regulated by nuclear factor kappaB (NF- $\kappa \mathrm{B})$ and activator protein 1 (AP-1) (61-63). $\mathrm{NF}-\kappa \mathrm{B}$ regulates the expression of various genes including those encoding cytokines, chemokines, and also participates in inflammasome regulation. All three pathways can activate NF$\kappa \mathrm{B}$ independently, but IRE $1 \alpha$ plays an essential role in inflammatory pathways (64). IRE1 interaction with TRAF2 (TNF Receptor Associated Factor 2) in response to ER stress leads to the recruitment of IKB kinase (IKK) which phosphorylates and subsequently degrades IKB (65), thereby activating NF- $\kappa \mathrm{B}$. PERK-eIF2 $\alpha$ signaling pathway halts overall protein synthesis. Thus, NF- $\kappa B$ to I $\mathrm{B}$ ratio in cell increases due to I $\kappa B$ 's shorter half-life than NF- $\kappa B$, which subsequently favors NF- $\kappa \mathrm{B}$ dependent transcription $(66,67)$. Activated IRE1 also interacts with TRAF2 and ASK1 that further activates the JNK in addition to the activation of $\mathrm{NF}-\kappa \mathrm{B}$ and leading to the AP1 activation (68-70). Genes transcribed by AP1 include cytokines such as tumor necrosis factor (TNF), keratinocyte growth factor (KGF), granulocyte-macrophage colony-stimulating factor (GMCSF), IL8, IL-1 receptor antagonists, and fibroblast growth factor receptor 1, implying that AP1 also plays a crucial role in the regulation of cytokine receptors (71).

All three major arms of UPR viz. PERK, ATF6, and IRE1 have a central role in immune regulation. In PERK signaling, ATF4 activates IL6 transcription in macrophages (72). Further, phosphorylation of eIF2 $\alpha$ upon activation of PERK signaling allows selective translation of mRNAs bearing upstream open reading frames (uORFs) in their $5^{\prime}$-untranslated regions (5'UTR), which might act as novel antigens for MHC-I presentation (73). IRE1 $\alpha$ undergoes phosphorylation by signals downstream to Toll-like receptors (TLRs). Phosphorylated IRE1 $\alpha$ induces unspliced $X B P 1 u$ mRNA splicing resulting in an active transcription factor, spliced XBP1 (XBP1s), which activates the 


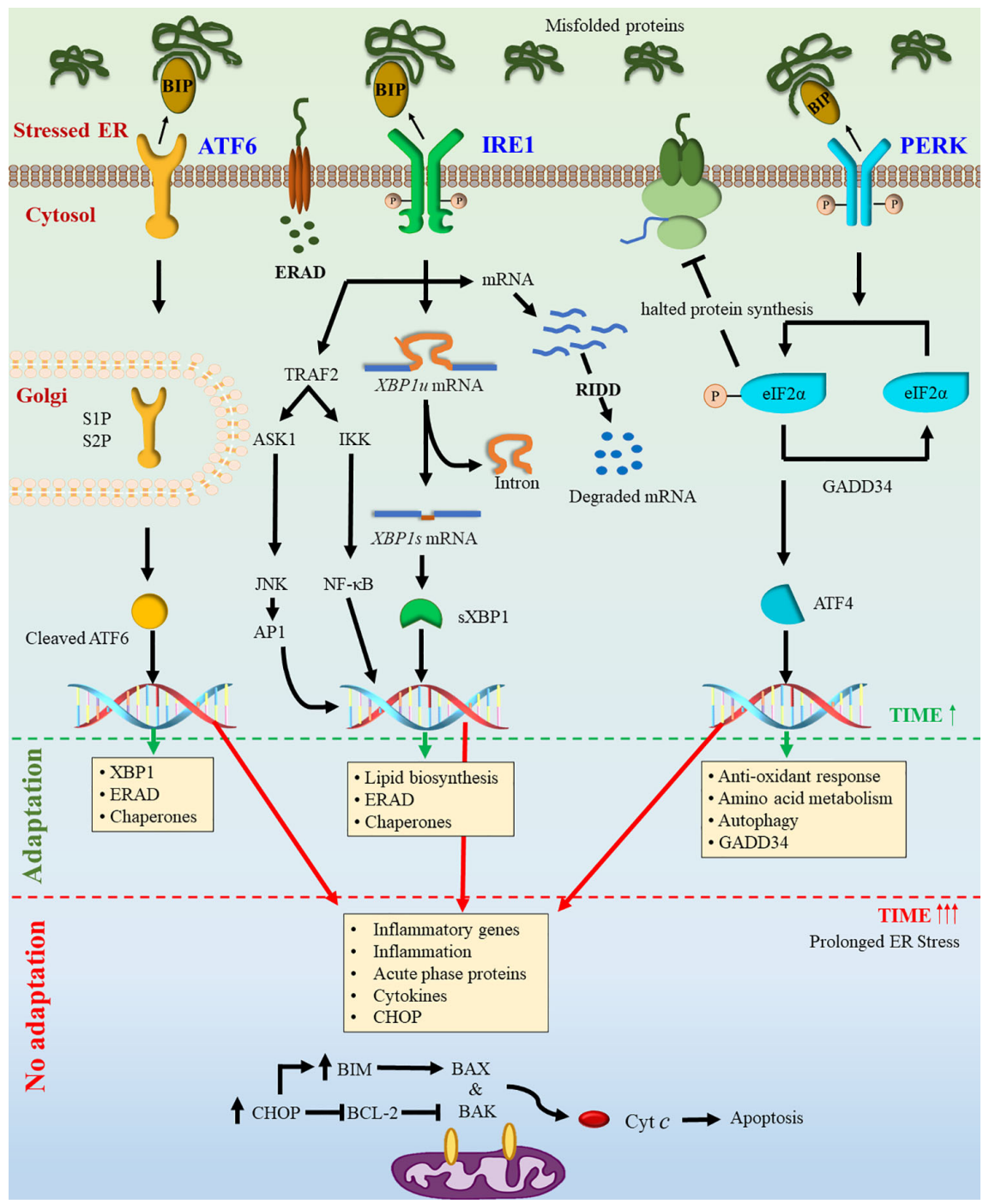

FIGURE 1 | Activation of unfolded protein response. Due to stress conditions, unfolded protein levels increase in the ER lumen. The dissociation of GRP78 from transmembrane sensors PERK, ATF6, and IRE1 leads to the activation of UPR signaling. Activation of IRE1 and PERK results in their oligomerization and transphosphorylation. Active IRE1 triggers the unconventional splicing of XBP1 $\mathrm{mRNA}$ resulting in the translation of an active transcription factor sXBP1. The active IRE1 can also interact with JNK and TRAF2 and thereby activating downstream signaling. The activation of ATF6 leads to its translocation to the Golgi and its proteolytic cleavage, resulting in a transcriptionally active form. Activation of PERK triggers phosphorylation of elF2 $\alpha$ leading to global translational attenuation and favoring translation of ATF4. Activation of all three pathways activate downstream transcriptional machinery resulting in expression of target genes to overcome the stress conditions. Persistent and excessive ER stress may lead to activation of mitochondria mediated cell death pathway.

production of pro-inflammatory cytokines in macrophages (74). IRE1 $\alpha / \mathrm{XBP} 1 \mathrm{~s}$ also contributes to homeostasis and survival of $\mathrm{CD} 8 \alpha^{+}$conventional dendritic cells (DCs) (75). Furthermore, it has also been reported that XBP1s may regulate the expression of TNF and IL6 in macrophages (74). Notably, transcriptional targets of ATF6 include XBP1 and thus ATF6 is also recognized as a regulator of the IRE1/XBP1 axis (76-78). Interestingly, it has been reported that cleaved ATF6 can act as an enhancer and increase the CREBH-mediated (cAMP response element-binding protein $\mathrm{H})$ acute inflammatory response, indicating a link between ATF6 and inflammation (79).

\section{IMPLICATIONS OF LOCALIZED AND PERIPHERAL ER STRESS IN VITILIGO}

\section{ER Stress in the Skin Microenvironment}

In the skin, ER stress may be induced by various endogenous as well as exogenous stressors such as UV irradiation, trauma, and chemical stressors (Table S3). Interestingly, chemical stressors including phenolic derivatives such as rhododendrol, hydroquinone, MBEH (mono benzyl ether of hydroquinone), and 4-TBP (4-tertiary butyl phenol) present in the cosmetic skin whitening agents have been identified to induce UPR mediated 
melanocyte death (80-84). Importantly, physiological ER stress is required for the maintenance of normal biological functions including keratinocyte differentiation in the skin (85). ER stresssignaled UPR was found to be activated during epidermal keratinocyte differentiation (85-87). Expression of UPR activation markers such as sXBP1, CHOP, and GRP78 is increased in the undifferentiated/proliferative stage of keratinocytes during their differentiation $(85,88)$. Furthermore, $\mathrm{CD}^{+} \mathrm{T}$ cells are found to be essential effectors of melanocyte destruction in vitiligo patients $(89,90)$. The recruitment of $\mathrm{CD}^{+} \mathrm{T}$ cells to skin lesions is carried out by the IFN- $\gamma$-mediated T cell chemokine receptor, C-X-C motif chemokine receptor 3 (CXCR3), and its ligands CXCL9, CXCL10, and CXCL11, which are found to be abundant in skin biopsy specimens from vitiligo patients (91). The blockade of this pathway mitigated the vitiligo in mice as well as in human subjects $(92,93)$. IRE1 $\alpha / s X B P 1$ signaling in stressed keratinocytes augmented the levels of CXCL16, which is involved in $\mathrm{CD}^{+} \mathrm{T}$ cell recruitment to skin lesions (94).

\section{ER Stress in Peripheral System}

Peripheral blood mononuclear cells (PBMCs) play a critical role in immune response, metabolism, and communication with other cells. PBMCs of vitiligo patients were reported to have metabolic deregulations and oxidative stress, similar to those found in melanocytes and the lesional epidermis (95-97). Histological studies have demonstrated that infiltration of $\mathrm{CD}^{+} \mathrm{T}$ cells occurs surrounding the vitiligo lesions (98-101). Hence, the role of ER stress in the regulation of the peripheral immune system may be interesting in understanding vitiligo pathogenesis. The UPR signaling is involved in the differentiation, proliferation, and homeostasis of both $\mathrm{B}$ and $\mathrm{T}$ cells. In the presence of a differentiation stimulus, both $\mathrm{B}$ and $\mathrm{T}$ cells increase GRP78 protein levels, initiate $X B P 1$ splicing, and induce ATF6 signaling (102-105). The inhibition of GRP78, ATF6, or XBP1 greatly reduces plasma cell differentiation and their efficacy upon maturation $(102,106)$. Cell fate determines whether UPR signaling is maintained for example, early B cells exhibit active UPR signaling, but it is absent in mature B cells. Similarly, $\mathrm{CD}^{-}{ }^{-}$ $\mathrm{CD} 8^{-}$progenitor $\mathrm{T}$ cells do not exhibit UPR, but greatly increase $\mathrm{UPR}$ during maturation as $\mathrm{CD} 4^{+} / \mathrm{CD} 8^{+} \mathrm{T}$ cells. Upon differentiation to $\mathrm{CD} 4^{+} \mathrm{T}$ cells, the UPR is once again repressed (103). $\mathrm{CD}^{+} \mathrm{T}$ cells play a major role in anti-melanocyte autoimmunity in vitiligo. Infection of mice with lymphocytic choriomeningitis virus (LCMV) resulted in the upregulation of spliced and unspliced XBP1 that further enhanced differentiation of $\mathrm{CD}^{+} \mathrm{T}$ cells (104). ER stress chaperone, GRP78 also plays an essential role in the regulation of granzyme $\mathrm{B}$ in $\mathrm{CD} 8^{+} \mathrm{T}$ cells and $\mathrm{CD}^{+}$intraepithelial lymphocytes. $\mathrm{CD}^{+} \mathrm{T}$ cells of heterozygous GRP78 mouse model had reduced granzyme $B$ secretion and cytotoxicity. This granzyme B deficiency was due to a reduction in IL-2 mediated proliferation, as exogenous IL-2 helped to partially restore granzyme B expression (107).

ER stress is also implicated in the regulation of Treg cells. Human Treg clones had elevated IL-10 production when treated with thapsigargin, an activator of ER stress and UPR, in an eIF2 $\alpha$ phosphorylation-dependent manner (108). Loss of ATF4 led to a modest increase in FOXP3 mRNA expression in mouse $\mathrm{CD} 4^{+}$ cells differentiated under $\mathrm{T}$ regulatory conditions in a high oxidizing environment (109). Recently, decreased levels of NFATs and FOXP3 are reported in Tregs of generalized vitiligo patients which may impair Treg cell function along with reduced IL10 and CTLA4 levels (18-20).

\section{PLAUSIBLE INVOLVEMENT OF ER STRESS IN VITILIGO AUTOIMMUNITY}

The ER stress may contribute to the development of autoimmunity through the recognition of misfolded proteins by autoreactive immune cells. Release of neo-autoantigens and UPR-related autoantigens by stressed cells, subsequently provoke autoimmunity. ER stress may indirectly contribute to autoimmunity through impairment of immune-tolerance mechanisms in cells with an abnormal UPR and conferring resistance to UPR mediated apoptosis in autoreactive cells by upregulating ERAD-associated proteins (48). Under certain pathophysiological conditions, several ER chaperones are translocated to the cell surface or released in extracellular space, which may serve as damage-associated molecular patterns (DAMPS) and attract the innate immune system to target "abnormal" cells for phagocytosis leading to subsequent activation of adaptive immunity (110). These phenomena have been established in various autoimmune disorders such as type I diabetes (T1D), rheumatoid arthritis (RA), systemic lupus erythematosus (SLE) $(111,112)$. Interestingly, one of the essential ER chaperones, GRP78 has immunomodulatory functions upon cell surface translocation. Vig et al. (112) have demonstrated that sGRP78 serves as a pro-apoptotic signaling receptor in beta cells and postulated that inflamed beta cells set up a self-destructing feedback loop through the combined surface translocation and secretion of GRP78. These findings suggest an important role of surface translocated GRP78 in autoimmune destruction of target cells. Though the role of sGRP78 is not yet established in melanocyte destruction, a few studies on other chaperones have encouraged researchers to hypothesize its role in melanocyte destruction in vitiligo. Kroll et al. (113) have observed that 4-tertiary butyl-phenol (4-TBP) induced expression and release of HSP70 by PIG3V melanocytes (immortalized vitiligo melanocytes). Further, it induced expression of tumor necrosis factor-related apoptosis-inducing ligand (TRAIL) on the membrane and activated DC effector functions towards the stressed melanocytes. Interestingly, they observed increased expression of TRAIL and CD11c+ dendritic cell infiltration in the perilesional skin of vitiligo patients. This suggested that HSP70 release by stressed melanocytes may facilitate DC activation leading to melanocyte destruction in vitiligo (113). In another exciting study, Zhang et al. have reported oxidative stress-induced translocation of calreticulin (CRT) on melanocyte surface (114). They observed that CRT surface translocation (sCRT) on melanocytes induced expression of pro-inflammatory cytokines such as IL-6 and TNF-a by human PBMCs in vitro. Elevated sCRT was concordant with decreased membrane CD47 expression; CD47 acts as a "don't eat 
me" signal in contrast to "eat me" signal of CRT, resulting in immunogenic cell death $(114,115)$. Moreover, a positive correlation of plasma CRT levels was observed with the area affected and the activity of the disease in vitiligo patients suggesting CRT's role in vitiligo pathogenesis (114). These studies led us to postulate the potential role of ER stress response proteins in the initial development of autoimmune response against stressed melanocytes.

\section{FUTURE PROSPECTS AND TRANSLATIONAL RELEVANCE OF ER STRESS IN VITILIGO}

As per the recent understanding, it is clear that the ER stress is at the verge of oxidative stress and inflammatory/immunoregulatory response in the cell, making it an ideal therapeutic target. However, the core UPR signaling involved in melanocyte biology and vitiligo pathomechanism is not much explored. A few studies demonstrate that therapeutic agents modulating ER stress can be promising for vitiligo treatment. Zhu et al. (116) have reported that Baicalin attenuated the progression and reduced the area of depigmentation in the C57BL/6 mouse model of vitiligo. Furthermore, they observed that Baicalin stimulated the proliferation of melanocytes in depigmented skin, which further led to a decrease in $\mathrm{CD}^{+} \mathrm{T}$ cell infiltration and the expression of CXCL10 and CXCR3 in mice skin. Interestingly, they also observed significantly decreased levels of IL-6, TNF- $\alpha$, IFN- $\gamma$, and IL-13 in sera of vitiligo mice models (116). Baicalin is an active ingredient of $S$. baicalensis, which is reported to protect cardio-myocytes and chondrocytes from ER stress-induced apoptosis $(117,118)$. Bilobalide is one of the active components of $\mathrm{G}$. biloba extract. $\mathrm{Lu}$ et al. reported that pre-treatment with bilobalide could protect melanocytes from oxidative damage by inhibiting $\mathrm{H}_{2} \mathrm{O}_{2}$ induced cytotoxicity. It also inhibited eIF2 $\alpha$ phosphorylation and downregulated CHOP expression (119). However, the exact mechanism of ER stress modulation by these herbal extracts is not clear. Apart from these, therapeutic strategies aiming to improve protein-folding capacity during ER stress might also be promising. Chemical chaperones such as Tauro-ursodeoxycholic acid (TUDCA) and 4-phenyl butyrate (PBA) can improve protein folding in the ER. Success in the alleviation of ER stress-induced hyperglycemia, restoration of insulin sensitivity, and fatty liver disease amelioration was observed upon TUDCA and 4-PBA treatments in obese mice (120). Cao et al. have reported that TUDCA and 4-PBA decreased ER stress in the intestinal epithelium leading to reduced dextran sodium sulfate (DSS) induced colitis severity (121). Moreover, it was found that 4-PBA leads to a decrease in lipopolysaccharide (LPS)-induced lung inflammation through modulating ER stress, $\mathrm{NF}-\kappa \mathrm{B}$, and hypoxia-inducing factor $1 \alpha(\mathrm{HIF} 1 \alpha)$ signaling (122). Nevertheless, further studies to understand the molecular mechanism of ER stress signaling in melanocytes, neighboring keratinocytes, and circulatory as well as infiltrated immune cells are warranted for the development of novel targeted and personalized ER stress modulating therapeutics for vitiligo.

\section{CONCLUSIONS}

Over the decades, the role of UPR in the pathogenesis of various autoimmune disorders is well established. However, its role in anti-melanocyte autoimmunity in vitiligo is yet to be unraveled.

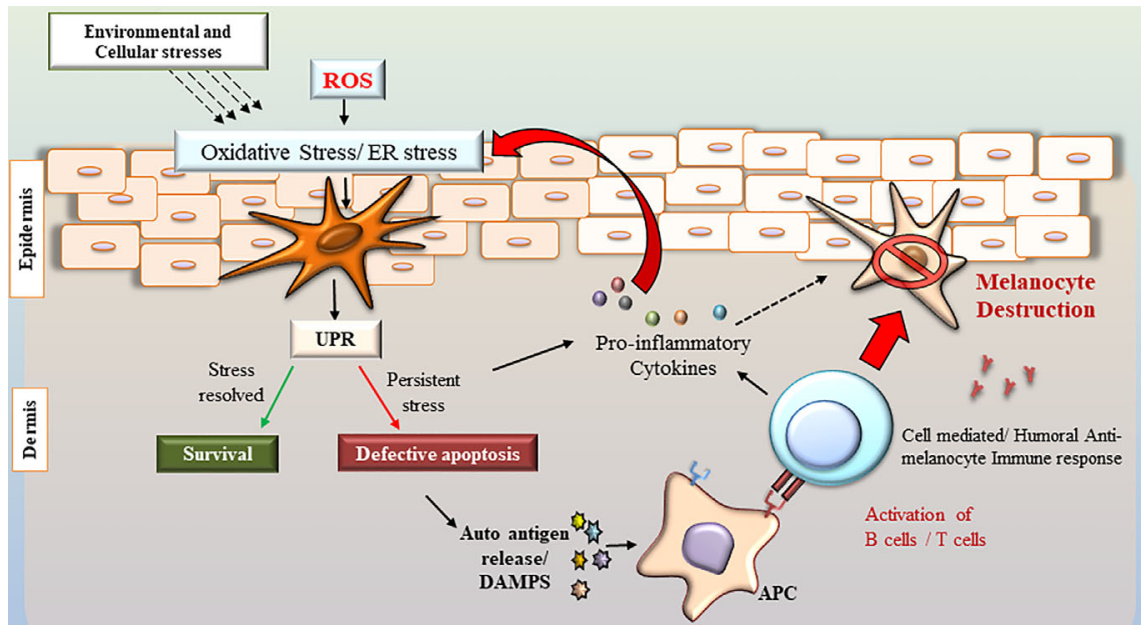

FIGURE 2 | Role of ER stress, oxidative stress, inflammation, and autoimmunity in vitiligo pathogenesis. Various exogenous and endogenous stressors in the skin result in oxidative stress and ER stress. ER stress activates the UPR signaling to resolve the stress. However, prolonged ER stress and defective UPR may lead to activation of inflammatory transcriptional program and release of proinflammatory cytokines, which generates further ER stress and oxidative stress. Further, the defective apoptosis of melanocytes might result in the release of misfolded/unfolded proteins that can potentially act as autoantigens and might be identified as damage-associated molecular patterns by the immune cells. The antigen presenting cells (APC) may process and present the altered proteins/peptides generating novel epitopes, which in turn will activate target B and T cells, resulting in an anti-melanocyte autoimmune response. 
Although extensive research has been done to decipher the conundrum of the underlying molecular mechanisms of melanocyte destruction, the role of UPR in vitiligo still remains an enigma. Several studies have uncovered essential direct and indirect mechanistic links that established cross-talk among oxidative stress, ER stress, and autoimmunity, which appears to be crucial in vitiligo pathogenesis (Figure 2). A wide range of studies has demonstrated that ER stress-activated UPR plays an essential role in the regulation and maintenance of innate as well as adaptive immunity. Though the role of ER stress in affecting immunity at systemic as well as tissue level is not well understood, a defective UPR might result in organ-specific autoimmunity. Since the immune response is a multi-step process, depending on the microenvironment of the cell, UPR can promote cell survival or death. This review suggests that the UPR is orchestrating the cell fate differently in the active participating immune cells and the target melanocytes. The genetic predisposition and the microenvironment of the target tissue play a major role in deciding the cell fate. Thus, further studies deciphering the tissue/cell type-specific UPR and developing UPR modulating strategies accordingly are warranted. Future research work in this direction will be promising in the development of novel immunotherapeutics for vitiligo.

\section{REFERENCES}

1. Shajil EM, Chatterjee S, Agrawal D, Bagchi T, Begum R. Vitiligo: Pathomechanisms and genetic polymorphism of susceptible genes. Indian J Exp Biol (2006) 44:526-39.

2. Laddha NC, Dwivedi M, Mansuri MS. Vitiligo: Interplay between oxidative stress and immune system. Exp Dermatol (2013a) 22:245-50. doi: 10.1111/ exd.12103

3. Kundu RV, Mhlaba JM, Rangel SM, Le Poole IC. The Convergence Theory For Vitiligo: A Reappraisal. Exp Dermatol (2019) 28:647-55. doi: 10.1111/ exd.13677

4. Zhang XJ, Chen JJ, Liu JB. The genetic concept of vitiligo. J Dermatol Sci (2005) 39:137-46. doi: 10.1016/j.jdermsci.2005.06.004

5. Mansuri MS, Singh M, Dwivedi M, Laddha NC, Marfatia YS, Begum R. miRNA profiling revealed differentially expressed miRNA signatures from skin of non-segmental vitiligo patients. Br J Dermatol (2014a) 1:1263-7. doi: 10.1186/1755-8166-7-S1-P118

6. Mansuri MS, Singh M, Begum R. miRNA signatures and transcriptional regulation of their target genes in vitiligo. J Dermatol Sci (2016a) 84:50-8. doi: $10.1016 /$ j.jdermsci.2016.07.003

7. Schallreuter KU, Wood JM, Berger J. Low catalase levels in the epidermis of patients with vitiligo. J Invest Dermatol (1991) 97:1081-5. doi: 10.1111/ 1523-1747.ep12492612

8. Schallreuter KU, Wood JM, Ziegler I. Defective tetrahydrobiopterin and catecholamine biosynthesis in the depigmentation disorder vitiligo. BBA Mol Basis Dis (1994a) 1226:181-92. doi: 10.1016/0925-4439(94)90027-2

9. Schallreuter KU, Wood JM, Pittelkow MR. Regulation of melanin biosynthesis in the human epidermis by tetrahydrobiopterin. Science (1994b) 11(263):1444-6. doi: 10.1126/science.8128228

10. Dell'Anna ML, Maresca V, Briganti S. Mitochondrial impairment in peripheral blood mononuclear cells during the active phase of vitiligo. J Invest Dermatol (2001) 117:908-13. doi: 10.1046/j.0022-202X.2001.01459.x

11. Shajil EM, Begum R. Antioxidant status of segmental and non-segmental vitiligo. Pigment Cell Res (2006) 19:179-80. doi: 10.1111/j.1600-0749.2006.00299.x

12. Westerhof W, D'Ischia M. Vitiligo puzzle: The pieces fall in place. Pigment Cell Res (2007) 20:345-59. doi: 10.1111/j.1600-0749.2007.00399.x

13. Luiten RM, Van Den Boorn JG, Konijnenberg D. Autoimmune destruction of skin melanocytes by perilesional $\mathrm{T}$ cells from vitiligo patients. J Invest Dermatol (2009) 129:2220-32. doi: 10.1038/jid.2009.32

\section{AUTHOR CONTRIBUTIONS}

SJ and RB developed the concept. SJ, JM, JV, and NS performed a literature survey contributed to manuscript writing. RB contributed to the critical revision and approval of the article. All authors contributed to the article and approved the submitted version.

\section{FUNDING}

RB thanks financial support from the Science \& Engineering Research Board (SERB), Government of India (Grant No. EMR/ 2016/001565) and SJ thanks the University Grants Commission (UGC) for Senior Research Fellowship.

\section{SUPPLEMENTARY MATERIAL}

The Supplementary Material for this article can be found online at: https://www.frontiersin.org/articles/10.3389/fimmu.2020. 624566/full\#supplementary-material

14. Dwivedi M, Laddha NC, Arora P, Marfatia YS, Begum R. Decreased regulatory T-cells and $\mathrm{CD} 4(+) / \mathrm{CD} 8(+)$ ratio correlate with disease onset and progression in patients with generalized vitiligo. Pigment Cell Melanoma Res (2013a) 26(4):586-91. doi: 10.1111/pcmr.12105

15. Dwivedi M, Laddha NC, Weetman AP, Begum R, Kemp H. Vitiligo-A Complex Autoimmune Skin Depigmenting. Autoimmune Diseases. In: K Chatzidionysiou, ed. Autoimmunity - Pathogenesis, Clinical Aspects and Therapy of Specific Autoimmune Diseases. Intech- open science/open minds (2015a). p. 153. doi: 10.5772/59762

16. Dwivedi M, Kemp EH, Laddha NC, Mansuri MS, Weetman AP, Begum R. Regulatory T cells in Vitiligo: Implications for pathogenesis and therapeutics. Autoimmun Rev (2015b) 14:49-56. doi: 10.1016/j.autrev.2014.10.002

17. Singh M, Kotnis A, Jadeja SD, et al. Cytokines: the yin and yang of vitiligo pathogenesis. Expert Rev Clin Immunol (2018a) 15(2):177-88. doi: 10.1080/ 1744666X.2019.1550358

18. Giri PS, Dwivedi M, Laddha NC, Begum R, Bharti AH. Altered Expression of Nuclear Factor of Activated T Cells, Forkhead Box P3, and ImmuneSuppressive Genes in Regulatory T Cells of Generalized Vitiligo Patients. Pigment Cell Melanoma Res (2020a) 33:566-78. doi: 10.1111/pcmr.12862

19. Giri PS, Dwivedi M, Begum R. Decreased suppression of $\mathrm{CD}^{8+}$ and $\mathrm{CD}^{4+} \mathrm{T}$ cells by peripheral Regulatory $\mathrm{T}$ cells in Generalized Vitiligo due to reduced NFATC1 and FOXP3 proteins. Exp Dermatol (2020b) 29:759-75. doi: $10.1111 /$ exd.14157

20. Giri PS, Patel S Begum R, Dwivedi M. Association of FOXP3 and GAGE10 Promoter Polymorphisms and Decreased FOXP3 Expression in Regulatory $\mathrm{T}$ cells with Susceptibility to Generalized Vitiligo in Gujarat Population. Gene (2020c) 09:145295. doi: 10.1016/j.gene.2020.145295

21. Birlea SA, Ahmad FJ, Uddin RM, Ahmad S, Pal SS, Begum R, et al. Association of Generalized Vitiligo with MHC Class II Loci in Patients from the Indian Subcontinent. I Invest Dermatol (2013) 133:1369-72. doi: 10.1038/jid.2012.501

22. Dwivedi M, Laddha NC, Imran M, Shah BJ, Begum R. Cytotoxic Tlymphocyte-associated antigen-4 (CTLA-4) in isolated vitiligo: A genotype-phenotype correlation. Pigment Cell Melanoma Res (2011) 24:737-40. doi: 10.1111/j.1755-148X.2011.00892.x

23. Dwivedi M, Laddha NC, Begum R. Correlation of increased MYG1 expression and its promoter polymorphism with disease progression and higher susceptibility in vitiligo patients. J Dermatol Sci (2013b) 71:195-202. doi: 10.1016/j.jdermsci.2013.04.026 
24. Dwivedi M, Laddha NC, Shah K, Shah BJ, Begum R. Involvement of interferon-gamma genetic variants and intercellular adhesion molecule-1 in onset and progression of generalized Vitiligo. J Interferon Cytokine Res (2013c) 33:646-59. doi: 10.1089/jir.2012.0171

25. Dwivedi M, Laddha NC, Mansuri MS, Marfatia YS, Begum R. Association of NLRP1 genetic variants and mRNA overexpression with generalized vitiligo and disease activity in a Gujarat population. Br J Dermatol (2013d) 169:1114-25. doi: 10.1111/bjd.12467

26. Imran M, Laddha NC, Dwivedi M, Mansuri MS, Singh J, Rani R, et al. Interleukin- 4 genetic variants correlate with its transcript and protein levels in patients with vitiligo. Br J Dermatol (2012) 1:314-23. doi: 10.1111/j.13652133.2012.11000.x

27. Jadeja SD, Mansuri MS, Singh M, Dwivedi M, Laddha NC, Begum R. A casecontrol study on association of proteasome subunit beta 8 (PSMB8) and transporter associated with antigen processing 1 (TAP1) polymorphisms and their transcript levels in vitiligo from Gujarat. PLoS One (2017) 10(12): e0180958. doi: 10.1371/journal.pone.0180958

28. Jadeja SD, Mansuri MS, Singh M, Patel H, Marfatia YS, Begum R. Association of elevated homocysteine levels and Methylenetetrahydrofolate reductase (MTHFR) $1298 \mathrm{~A}>\mathrm{C}$ polymorphism with Vitiligo susceptibility in Gujarat. J Dermatol Sci (2018) 90:112-22. doi: 10.1016/j.jdermsci.2018. 01.003

29. Laddha NC, Dwivedi M, Shajil EM, Prajapati H, Marfatia YS, Begum R. Association of PTPN22 1858C/T polymorphism with vitiligo susceptibility in Gujarat population. J Dermatol Sci (2008) 49:260-2. doi: 10.1016/ j.jdermsci.2007.10.002

30. Laddha NC, Dwivedi M, Begum R. Increased Tumor Necrosis Factor (TNF)$\alpha$ and Its Promoter Polymorphisms Correlate with Disease Progression and Higher Susceptibility towards Vitiligo. PLoS One (2012) 7:e52298. doi: 10.1371/journal.pone.0052298

31. Laddha NC, Dwivedi M, Gani AR. Involvement of superoxide dismutase isoenzymes and their genetic variants in progression of and higher susceptibility to vitiligo. Free Radic Biol Med (2013b) 65:1110-25. doi: 10.1016/j.freeradbiomed.2013.08.189

32. Laddha NC, Dwivedi M, Gani AR. Tumor Necrosis Factor B (TNFB) Genetic Variants and Its Increased Expression Are Associated with Vitiligo Susceptibility. PLoS One (2013c) 8:1-11. doi: 10.1371/journal. pone. 0081736

33. Laddha NC, Dwivedi M, Mansuri MS. Role of oxidative stress and autoimmunity in onset and progression of vitiligo. Exp Dermatol (2014a) 23:352-3. doi: 10.1111/exd.12372

34. Laddha NC, Dwivedi M, Mansuri MS, Singh M, Patel HH, Agarwal N, et al. Association of Neuropeptide Y (NPY), Interleukin-1B (IL1B) Genetic Variants and Correlation of IL1B Transcript Levels with Vitiligo Susceptibility. PLoS One (2014b) 15(9):e107020. doi: 10.1371/journal.pone. 0107020

35. Mansuri MS, Laddha NC, Dwivedi M, Patel D, Alex T, Singh M, et al. Genetic variations (Arg5Pro and Leu6Pro) modulate the structure and activity of GPX1 and genetic risk for vitiligo. Exp Dermatol (2016b) 25:654-7. doi: 10.1111/exd.13007

36. Mansuri MS, Jadeja SD, Singh M. The catalase gene promoter and $5^{\prime}$ untranslated region variants lead to altered gene expression and enzyme activity in vitiligo. Br J Dermatol (2017) 177:1590-600. doi: 10.1111/bjd.15681

37. Mansuri MS, Singh M, Jadeja SD, Begum R. Association of glucose 6phosphate dehydrogenase (G6PD) 3'UTR polymorphism with vitiligo and in vitro studies on G6PD inhibition in melanocytes. J Dermatol Sci (2019) 93:133-5. doi: 10.1016/j.jdermsci.2018.12.001

38. Shajil EM, Laddha NC, Chatterjee S, Gani AR, Malek RA, Shah BJ, et al. Association of catalase T/C exon 9 and glutathione peroxidase codon 200 polymorphisms in relation to their activities and oxidative stress with vitiligo susceptibility in Gujarat population. Pigment Cell Res (2007) 20:405-7. doi: 10.1111/j.1600-0749.2007.00406.x

39. Singh A, Sharma P, Kar HK, Sharma VK, Tembhre MK, Gupta S, et al. HLA alleles and amino-acid signatures of the peptide-binding pockets of HLA molecules in vitiligo. J Invest Dermatol (2012) 132:124-34. doi: 10.1038/ jid.2011.240

40. Singh M, Mansuri MS, Jadeja SD, Marfatia YS, Begum R. Association of Interleukin 1 Receptor Antagonist (IL1RN) intron 2 VNTR polymorphism with vitiligo susceptibility in Gujarat population. Ind J Dermatol Venereol Leprol (2018b) 84:285-91. doi: 10.4103/ijdvl.IJDVL_1_17

41. Singh M, Jadeja SD, Vaishnav J, Mansuri MS, Shah C, Mayatra JM, et al. Investigation of the Role of Interleukin 6 in Vitiligo Pathogenesis. Immunol Invest (2020) 30:1-8. doi: 10.1080/08820139.2020.1813756

42. Boissy RE, Liu YY, Medrano EE, Nordlund JJ. Structural aberration of the rough endoplasmic reticulum and melanosome compartmentalization in long-term cultures of melanocytes from vitiligo patients. J Invest Dermatol (1991) 97:395-404. doi: 10.1111/1523-1747.ep12480976

43. Tu BP, Weissman JS. Oxidative protein folding in eukaryotes: Mechanisms and consequences. J Cell Biol (2004) 164:341-6. doi: 10.1083/jcb.200311055

44. Van der Vlies D, Makkinje M, Jansens A. Oxidation of ER resident proteins upon oxidative stress: Effects of altering cellular redox/antioxidant status and implications for protein maturation. Antioxid Redox Signal (2003) 5:381-7. doi: $10.1089 / 152308603768295113$

45. Malhotra JD, Kaufman RJ. Endoplasmic reticulum stress and oxidative stress: a vicious cycle or a double-edged sword? Antioxid Redox Signal (2007) 9:2277-93. doi: 10.1089/ars.2007.1782

46. Anbar T, Zuel-Fakkar NM, Matta MF, Arbab MMI. Elevated homocysteine levels in suction-induced blister fluid of active vitiligo lesions. Eur J Dermatol (2016) 26:64-7. doi: 10.1684/ejd.2015.2682

47. Tsai TY, Kuo CY, Huang YC. Serum homocysteine, folate, and vitamin B 12 levels in patients with vitiligo and their potential roles as disease activity biomarkers: A systematic review and meta-analysis. J Am Acad Dermatol (2019) 80:646-54.e5. doi: 10.1016/j.jaad.2018.08.029

48. Todd DJ, Lee AH, Glimcher LH. The endoplasmic reticulum stress response in immunity and autoimmunity. Nat Rev Immunol (2008) 8:663-74. doi: $10.1038 /$ nri2359

49. Mansuri MS, Singh M, Jadeja SD, Gani AR, Patel R, Dwivedi M. Could ER Stress Be A Major Link Between Oxidative Stress And Autoimmunity In Vitiligo? J Pigment Disord (2014b) 01:123. doi: 10.4172/2376-0427.1000123

50. Ramirez MU, Hernandez SR, Soto-Pantoja DR, Cook KL. Endoplasmic reticulum stress pathway, the unfolded protein response, modulates immune function in the tumor microenvironment to impact tumor progression and therapeutic response. Int J Mol Sci (2020) 25(21):169. doi: 10.3390/ ijms 21010169

51. Schuck S, Prinz WA, Thorn KS, Voss C, Walter P. Membrane expansion alleviates endoplasmic reticulum stress independently of the unfolded protein response. J Cell Biol (2009) 16(187):525-36. doi: 10.1083/ jcb.200907074

52. Kozutsumi $\mathrm{Y}$, Segal M, Normington K. The presence of malfolded proteins in the endoplasmic reticulum signals the induction of glucose-regulated proteins. Nature (1988) 332:462-4. doi: 10.1038/332462a0

53. Wang XZ, Harding HP, Zhang Y. Cloning of mammalian Ire1 reveals diversity in the ER stress responses. EMBO J (1998) 17:5708-17. doi: 10.1093/emboj/17.19.5708

54. Haze K, Yoshida H, Yanagi H. Mammalian transcription factor ATF6 is synthesized as a transmembrane protein and activated by proteolysis in response to endoplasmic reticulum stress. Mol Biol Cell (1999) 10:3787-99. doi: $10.1091 / \mathrm{mbc} \cdot 10.11 .3787$

55. Huang G, Yao J, Zeng W. ER stress disrupts Ca2+-signaling complexes and $\mathrm{Ca} 2+$ regulation in secretory and muscle cells from PERK-knockout mice. J Cell Sci (2006) 119:153-61. doi: 10.1242/jcs.02731

56. Mu TW, Ong DS, Wang YJ, Balch WE, Yates JR3, Segatori L, et al. Chemical and biological approaches synergize to ameliorate protein-folding diseases. Cell (2008) 5(134):769-81. doi: 10.1016/j.cell.2008.06.037

57. Chen X, Shen J, Prywes R. The luminal domain of ATF6 senses endoplasmic reticulum (ER) stress and causes translocation of ATF6 from the er to the Golgi. J Biol Chem (2002) 277:13045-52. doi: 10.1074/jbc.M110636200

58. Oakes SA, Papa FR. The Role of Endoplasmic Reticulum Stress in Human Pathology. Annu Rev Pathol Mech Dis (2015) 10:173-94. doi: 10.1146/ annurev-pathol-012513-104649

59. Bettigole SE, Glimcher LH. Endoplasmic reticulum stress in immunity. Annu Rev Immunol (2015) 33:107-38. doi: 10.1146/annurev-immunol032414-112116

60. Grootjans J, Kaser A, Kaufman RJ, Blumberg RS. The unfolded protein response in immunity and inflammation. Nat Rev Immunol (2016) 16:46984. doi: $10.1038 /$ nri.2016.62 
61. Hotamisligil GS, Erbay E. Nutrient sensing and inflammation in metabolic diseases. Nat Rev Immunol (2008) 8:923-34. doi: 10.1038/nri2449

62. Walter P, Ron D. The unfolded protein response: From stress pathway to homeostatic regulation. Science (2011) 25(334):1081-6. doi: 10.1126/ science. 1209038

63. Verfaillie T, Garg AD, Agostinis P. Targeting ER stress induced apoptosis and inflammation in cancer. Cancer Lett (2013) 332:249-64. doi: 10.1016/ j.canlet.2010.07.016

64. Zhang K, Kaufman RJ. From endoplasmic-reticulum stress to the inflammatory response. Nature (2008) 454(7203):455-62. doi: 10.1038/ nature 07203

65. Hu P, Han Z, Couvillon AD, Kaufman RJ, Exton JH. Autocrine tumor necrosis factor alpha links endoplasmic reticulum stress to the membrane death receptor pathway through IRE1 $\alpha$-mediated NF- $\kappa B$ activation and down-regulation of TRAF2 expression. Mol Cell Biol (2006) 26(8):3071-84. doi: 10.1128/MCB.26.8.3071-3084.2006

66. Deng J, Lu PD, Zhang Y. Translational Repression Mediates Activation of Nuclear Factor Kappa B by Phosphorylated Translation Initiation Factor 2. Mol Cell Biol (2004) 24:10161-8. doi: 10.1128/mcb.24.23.10161-10168.2004

67. Tam AB, Mercado EL, Hoffmann A, Niwa M. ER Stress Activates NF- $\mathrm{KB}$ by Integrating Functions of Basal IKK Activity, IRE1 and PERK. PLoS One (2012) 7:e45078. doi: 10.1371/journal.pone.0045078

68. Luo D, He Y, Zhang H, Yu L, Chen H, Xu Z, et al. AIP1 is critical in transducing IRE1-mediated endoplasmic reticulum stress response. J Biol Chem (2018) 2(283):11905-12. doi: 10.1074/jbc.M710557200

69. Urano F, Wang XZ, Bertolotti A. Coupling of stress in the ER to activation of JNK protein kinases by transmembrane protein kinase IRE1. Science (2000) 287:664-6. doi: 10.1126/science.287.5453.664

70. Eferl R, Wagner EF. AP-1: A double-edged sword in tumorigenesis. Nat Rev Cancer (2003) 3:859-68. doi: 10.1038/nrc1209

71. Angel P, Szabowski A, Schorpp-Kistner M. Function and regulation of AP-1 subunits in skin physiology and pathology. Oncogene (2001) 20:2413-23. doi: 10.1038/sj.onc. 1204380

72. Iwasaki Y, Suganami T, Hachiya R, Shirakawa I, Kim-Saijo M, Tanaka M, et al. Activating transcription factor 4 links metabolic stress to interleukin-6 expression in macrophages. Diabetes (2014) 63:152-61. doi: 10.2337/db13-0757

73. Starck SR, Tsai JC, Chen K. Translation from the 5' untranslated region shapes the integrated stress response. Science (2016) 29(351):aad3867. doi: 10.1126/science.aad3867

74. Martinon F, Chen X, Lee AH, Glimcher LH. TLR activation of the transcription factor XBP1 regulates innate immune responses in macrophages. Nat Immunol (2010) 11:411-8. doi: 10.1038/ni.1857

75. Osorio F, Tavernier SJ, Hoffmann E. The unfolded-protein-response sensor IRE- $1 \alpha$ regulates the function of $\mathrm{CD} 8 \alpha+$ dendritic cells. Nat Immunol (2014) 15:248-57. doi: 10.1038/ni.2808

76. Yoshida H, Matsui T, Yamamoto A. XBP1 mRNA is induced by ATF6 and spliced by IRE1 in response to ER stress to produce a highly active transcription factor. Cell (2001) 107:881-91. doi: 10.1016/S0092-8674(01)00611-0

77. Lee K, Tirasophon W, Shen X. IRE1-mediated unconventional mRNA splicing and S2P-mediated ATF6 cleavage merge to regulate XBP1 in signaling the unfolded protein response. Genes Dev (2002) 15(16):452-66. doi: $10.1101 /$ gad. 964702

78. Yoshida H, Okada T, Haze K. ATF6 Activated by Proteolysis Binds in the Presence of NF-Y (CBF) Directly to the cis-Acting Element Responsible for the Mammalian Unfolded Protein Response. Mol Cell Biol (2000) 20:675567. doi: $10.1128 / \mathrm{mcb} \cdot 20.18 .6755-6767.2000$

79. Zhang K, Shen X, Wu J. Endoplasmic reticulum stress activates cleavage of CREBH to induce a systemic inflammatory response. Cell (2006) 10 (124):587-99. doi: 10.1016/j.cell.2005.11.040

80. Harris JE. Chemical-Induced Vitiligo. Dermatol Clin (2017) 35:151-61. doi: 10.1016/j.det.2016.11.006

81. Sasaki M, Kondo M, Sato K, Umeda M, Kawabata K, Takahashi Y, et al. Rhododendrol, a depigmentation-inducing phenolic compound, exerts melanocyte cytotoxicity via a tyrosinase-dependent mechanism. Pigment Cell Melanoma Res (2014) 27:754-63. doi: 10.1111/pcmr.12269

82. Toosi S, Orlow SJ, Manga P. Vitiligo-inducing phenols activate the unfolded protein response in melanocytes resulting in upregulation of IL6 and IL8. J Invest Dermatol (2012) 132:2601-9. doi: 10.1038/jid.2012.181
83. Tokura Y, Fujiyama T, Ikeya S, Tatsuno K, Aoshima M, Kasuya A, et al. Biochemical, cytological, and immunological mechanisms of rhododendrolinduced leukoderma. J Dermatol Sci (2015) 77:146-9. doi: 10.1016/ j.jdermsci.2015.02.001

84. Tsutsumi R, Sugita K, Abe Y, Hozumi Y, Suzuki T, Yamada N, et al. Leukoderma induced by rhododendrol is different from leukoderma of vitiligo in pathogenesis: A novel comparative morphological study. J Cutan Pathol (2019) 46:123-9. doi: 10.1111/cup.13396

85. Saheki Y, De Camilli P. Endoplasmic Reticulum-Plasma Membrane Contact Sites. Annu Rev Biochem (2017) 20(86):659-84. doi: 10.1146/annurevbiochem-061516-044932

86. Celli A, Sanchez S, Behne M. The epidermal Ca2+ gradient: Measurement using the phasor representation of fluorescent lifetime imaging. Biophys $J$ (2010) 3(98):911-21. doi: 10.1016/j.bpj.2009.10.055

87. Celli A, MacKenzie DS, Crumrine DS. Endoplasmic reticulum Ca2+ depletion activates XBP1 and controls terminal differentiation in keratinocytes and epidermis. Br J Dermatol (2011) 164:16-25. doi: 10.1111/ j.1365-2133.2010.10046.x

88. Phillips MJ, Voeltz GK. Structure and function of ER membrane contact sites with other organelles. Nat Rev Mol Cell Biol (2016) 17:69-82. doi: $10.1038 / \mathrm{nrm} .2015 .8$

89. Oyarbide-Valencia K, van den Boorn JG, Denman CJ. Therapeutic implications of autoimmune vitiligo T cells. Autoimmun Rev (2006) 5:486-92. doi: 10.1016/j.autrev.2006.03.012

90. Han D, Lerner AG, Walle LV. IRE1 a Kinase Activation Modes Control Alternate Endoribonuclease Outputs to Determine Divergent Cell Fates. Cell (2009) 138:562-75. doi: 10.1016/j.cell.2009.07.017

91. Ferrari SM, Fallahi P, Santaguida G. Circulating CXCL10 is increased in non-segmental vitiligo, in presence or absence of autoimmune thyroiditis. Autoimmun Rev (2017) 16:946-50. doi: 10.1016/j.autrev.2017.07.006

92. Harris JE, Harris TH, Weninger W. A mouse model of vitiligo with focused epidermal depigmentation requires IFN- $\gamma$ for autoreactive CD8+ T-cell accumulation in the skin. J Invest Dermatol (2012) 132:1869-76. doi: $10.1038 /$ jid.2011.463

93. Wang XX, Wang QQ, Wu JQ. Increased expression of CXCR3 and its ligands in patients with vitiligo and CXCL10 as a potential clinical marker for vitiligo. Br J Dermatol (2016) 174:1318-26. doi: 10.1111/bjd.14416

94. Riedhammer C, Weissert R. Antigen presentation, autoantigens, and immune regulation in multiple sclerosis and other autoimmune diseases. Front Immunol (2015) 6:322. doi: 10.3389/fimmu.2015.00322

95. Dell'Anna ML, Urbanelli S, Mastrofrancesco A, Camera E, Iacovelli P, Leone G, et al. Alterations of Mitochondria in Peripheral Blood Mononuclear Cells of Vitiligo Patients. Pigment Cell Res (2003) 16:553-9. doi: 10.1034/j.16000749.2003.00087.x

96. Giovannelli L, Bellandi S, Pitozzi V, Fabbri P, Dolara P, Moretti S. Increased Oxidative DNA Damage in Mononuclear Leukocytes in Vitiligo. Mutat Res (2004) 22(556):101-6. doi: 10.1016/j.mrfmmm.2004.07.005

97. Schallreuter KU, Moore J, Wood JM, Beazley WD, Peters EM, Marles LK, et al. Epidermal $\mathrm{H} 2 \mathrm{O} 2$ accumulation alters tetrahydrobiopterin (6BH4) recycling in vitiligo: identification of a general mechanism in regulation of all 6BH4-dependent processes? J Invest Dermatol (2001) 116(1):167-74. doi: 10.1046/j.1523-1747.2001.00220.x

98. Badri A, Todd PM, Garioch JJ, Gudgeon JE, Stewart DG. An Immunohistological Study of Cutaneous Lymphocytes in Vitiligo. J Pathol (1993) 170:149-55. doi: 10.1002/path.1711700209

99. Wankowicz-Kalinska A, Le Poole IC, van den Wijngaard R, Storkus WJ, Das PK. Melanocyte-Specific Immune Response in Melanoma and Vitiligo: Two Faces of the Same Coin? Pigment Cell Res (2003a) 16:254-60. doi: $10.1034 /$ j.1600-0749.2003.00038.x

100. Wańkowicz-Kalińska A, van den Wijngaard RM, Tigges BJ, Westerhof W, Ogg GS, Cerundolo V, et al. Immunopolarization of CD4+ and CD8+ $\mathrm{T}$ Cells to Type-1-like Is Associated with Melanocyte Loss in Human Vitiligo. Lab Invest (2003b) 83:683-95. doi: 10.1097/01.LAB.0000069521. 42488.1B

101. Wijngaard RM, Aten J, Scheepmaker A, Le Poole IC, Tigges AJ, Westerhof W, et al. Expression and Modulation of Apoptosis Regulatory Molecules in Human Melanocytes: Significance in Vitiligo. Br J Dermatol (2000) 143:57381. doi: $10.1046 /$ j.1365-2133.2000.03712.x 
102. Gass JN, Gifford NM, Brewer JW. Activation of an Unfolded Protein Response during Differentiation of Antibody-Secreting B Cells. J Biol Chem (2002) 277:49047-54. doi: 10.1074/jbc.M205011200

103. Brunsing R, Omori SA, Weber F, Bicknell A, Friend L, Rickert R, et al. B- and T-Cell Development Both Involve Activity of the Unfolded Protein Response Pathway. J Biol Chem (2008) 283:17954-61. doi: 10.1074/jbc.M801395200

104. Kamimura D, Bevan MJ. Endoplasmic Reticulum Stress Regulator XBP-1 Contributes to Effector CD8+T Cell Differentiation during Acute Infection. J Immunol (2008) 15(181):5433-41. doi: 10.4049/jimmunol.181.8.5433

105. Iwakoshi NN, Lee AH, Glimcher LH. The X-box binding protein-1 transcription factor is required for plasma cell differentiation and the unfolded protein response. Immunol Rev (2003) 194:29-38. doi: 10.1034/ j.1600-065x.2003.00057.x

106. Reimold AM, Iwakoshi NN, Manis J, Vallabhajosyula P, Szomolanyi-Tsuda E, Gravallese EM, et al. Plasma Cell Differentiation Requires the Transcription Factor XBP-1. Nature (2001) 412(6844):300-7. doi: 10.1038/35085509

107. Chang JS, Ocvirk S, Berger E, Kisling S, Binder U, Skerra A, et al. Endoplasmic reticulum stress response promotes cytotoxic phenotype of CD8 $\alpha \beta+$ intraepithelial lymphocytes in a mouse model for Crohn's diseaselike ileitis. J Immunol (2012) 189:1510-20. doi: 10.4049/jimmunol.1200166

108. Franco A, Almanza G, Burns JC, Wheeler M, Zanetti M. Endoplasmic Reticulum Stress Drives a Regulatory Phenotype in Human T-Cell Clones. Cell Immunol (2010) 266:1-6. doi: 10.1016/j.cellimm.2010.09.006

109. Yang X, Xia R, Yue C, Zhai W, Du W, Yang Q, et al. ATF4 regulates CD4+ T cell immune responses through metabolic reprogramming. Cell Rep (2018) 23(6):1754-66.

110. Wiersma VR, Michalak M, Abdullah TM. Mechanisms of Translocation of ER Chaperones to the Cell Surface and Immunomodulatory Roles in Cancer and Autoimmunity. Front Oncol (2015) 5:7. doi: 10.3389/fonc.2015.00007

111. Morito D, Nagata K. ER Stress Proteins in Autoimmune and Inflammatory Diseases. Front Immunol (2012) 15:2012.00048(3):48. doi: 10.3389/ fimmu.2012.00048

112. Vig S, Buitinga M, Rondas D. Cytokine-induced translocation of GRP78 to the plasma membrane triggers a pro-apoptotic feedback loop in pancreatic beta cells. Cell Death Dis (2019) 5(10):309. doi: 10.1038/s41419-019-1518-0

113. Kroll TM, Bommiasamy H, Boissy RE. 4-Tertiary butyl phenol exposure sensitizes human melanocytes to dendritic cell-mediated killing: Relevance to vitiligo. J Invest Dermatol (2005) 124:798-806. doi: 10.1111/j.0022202X.2005.23653.X

114. Zhang Y, Liu L, Jin L. Oxidative stress-induced calreticulin expression and translocation: New insights into the destruction of melanocytes. I Invest Dermatol (2014) 134:183-91. doi: 10.1038/jid.2013.268
115. Gardai SJ, McPhillips KA, Frasch SC, Janssen WJ, Starefeldt A, MurphyUllrich JE, et al. Cell-surface calreticulin initiates clearance of viable or apoptotic cells through trans-activation of LRP on sthe phagocyte. Cell (2005) 123:321-34. doi: 10.1016/j.cell.2005.08.032

116. Zhu Y, Zhong L, Peng J. The therapeutic effects of baicalin on vitiligo mice. Biol Pharm Bull (2019) 42:1450-5. doi: 10.1248/bpb.b19-00319

117. Shen M, Wang L, Yang G. Baicalin Protects the Cardiomyocytes from ER Stress-Induced Apoptosis: Inhibition of CHOP through Induction of Endothelial Nitric Oxide Synthase. PLoS One (2014) 9:e88389. doi: 10.1371/ journal.pone.0088389

118. Cao J, Zhang Y, Wang T, Li B. Endoplasmic Reticulum Stress Is Involved in Baicalin Protection on Chondrocytes From Patients With Osteoarthritis. Dose Response (2018) 16:155932581881063. doi: 10.1177/ 1559325818810636

119. Lu L, Wang S, Fu L. Bilobalide protection of normal human melanocytes from hydrogen peroxide-induced oxidative damage via promotion of antioxidase expression and inhibition of endoplasmic reticulum stress. Clin Exp Dermatol (2016) 41:64-73. doi: 10.1111/ced.12664

120. Ozcan U, Yilmaz E, Ozcan L, Furuhashi M, Vaillancourt E, Smith RO, et al. Chemical chaperones reduce ER stress and restore glucose homeostasis in a mouse model of type 2 diabetes. Science (2006) 25(313):1137-40. doi: 10.1126/science.1128294

121. Cao SS, Zimmermann EM, Chuang BM, Song B, Nwokoye A, Wilkinson JE, et al. The unfolded protein response and chemical chaperones reduce protein misfolding and colitis in mice. Gastroenterology (2013) 1(144):989-1000. doi: 10.1053/j.gastro.2013.01.023

122. Kim HJ, Jeong JS, Kim SR, Park SY, Chae HJ, Lee YC. Inhibition of endoplasmic reticulum stress alleviates lipopolysaccharide-induced lung inflammation through modulation of NF- $\kappa \mathrm{B} / \mathrm{HIF}-1 \alpha$ signaling pathway. Sci Rep (2013) 28(3):1-0. doi: 10.1038/srep01142

Conflict of Interest: The authors declare that the research was conducted in the absence of any commercial or financial relationships that could be construed as a potential conflict of interest.

Copyright (C) 2021 Jadeja, Mayatra, Vaishnav, Shukla and Begum. This is an openaccess article distributed under the terms of the Creative Commons Attribution License (CC BY). The use, distribution or reproduction in other forums is permitted, provided the original author(s) and the copyright owner(s) are credited and that the original publication in this journal is cited, in accordance with accepted academic practice. No use, distribution or reproduction is permitted which does not comply with these terms. 